\title{
EFEITO ALELOPÁTICO DE EUGENIA ASTRINGENS C. NO CRESCIMENTO INICIAL DE PICÃO-PRETO E ALFACE.
}

\author{
Winicius Botelho de Souza ${ }^{1}$ \\ Bruna Carminate ${ }^{2}$ \\ Bianca Ferreira Santos ${ }^{3}$ \\ Marcelo Barreto da Silva ${ }^{4}$
}

Resumo: A alelopatia é um fenômeno que ocorre largamente em comunidades de plantas, sendo um mecanismo pelo qual determinadas plantas interferem no desenvolvimento de outras. O objetivo deste trabalho foi avaliar a atividade alelopática do extrato aquoso das folhas de Eugenia astringens (C.) em relação ao efeito inibitório no crescimento inicial de Bidens pilosa L. (picão-preto) e Lactuca sativa $L$. (alface). Foi avaliada a atividade fitotóxica do extrato aquoso nas concentrações de 100\%, 75\%, 50\%, 25\% e $0 \%$ de extrato. Os parâmetros analisados foram comprimento das radículas e plântulas de picão-preto e alface. Os resultados indicaram que o extrato de E. astringens é capaz de inibidor o crescimento de plântulas e radículas, conferindo um potencial efeito alelopático contra o picão-preto e alface utilizadas como plantas alvo.

Palavras-chave: Eugenia; Herbicida; Plantas medicinais; Potencial alelopático.

\footnotetext{
${ }^{1}$ Agronomia/Universidade Federal do Espírito Santo, Centro Universitário Norte do Espirito Santo, Brasil. E-mail: winicius07@hotmail.com.

${ }^{2}$ Agronomia/Universidade Federal do Espírito Santo, Centro Universitário Norte do Espirito Santo, Brasil. E-mail: brunabcarminate@hotmail.com.

${ }^{3}$ Agronomia/Universidade Federal do Espírito Santo, Centro Universitário Norte do Espirito Santo, Brasil. E-mail: biancasantos123@hotmail.com.

4 Professor Titular/Universidade Federal do Espírito Santo, Centro Universitário Norte do Espirito Santo, Brasil. E-mail: marcelobarretodasilva@gmail.com.
} 